\title{
Anxiety Sensitivity and Obsessive-Compulsive Disorder: A Mini Review
}

\section{Sahel Khakpour ${ }^{1}$, Fayegh Yousefi ${ }^{2}$, Omid Saed ${ }^{3}$,}

1. Master of Clinical Psychology, Department of Clinical Psychology, Faculty of Medicine, Zanjan University of Medical Sciences, Zanjan, Iran. ORCID: 0000-0003-2536-3337

2. Associate Professor, Department of Psychiatry, Faculty of Medicine, Kurdistan University of Medical Sciences, Kurdistan, Sanandaj, Iran. ORCID: 0000-0001-5503-3326

3. Assistant Professor, Department of Clinical Psychology, Faculty of Medicine, Zanjan University of Medical Sciences, Zanjan, Iran. ORCID: 0000-0002-6070-6230

E-mail: o.saed@zums.ac.ir.

Received: $26 / 07 / 2018$

Accepted: 04/12/2018

\begin{abstract}
Obsessive-compulsive disorder (OCD) is one of the common psychological disorders that effects on the most aspects of individuals' life. In this regard, various studies have been explored to examine underlying factors involved in the psychopathology of this disorder. One of these factors is the anxiety sensitivity (AS) that refers to the fear of anxiety-related sensation. AS can play a role in this disorder in various ways, such as fear of losing control of mental abilities, fear of somatic sensation, and sensitivity to the negative evaluation of others. On the other hand, dimensional models of OCD revealed that each phenotypes of this disorder is associated with different aspects of the AS. Finally, examination of existing treatments suggests that AS can be considered as an important therapeutic factor in the treatment of OCD.
\end{abstract}

Keywords: Anxiety Sensitivity, Obsessive-compulsive disorder, Mini Review

How to cite this article : Khakpour S, Yousefi F, SaedO, Anxiety Sensitivity and Obsessive-Compulsive Disorder: A Mini Review. 2018; 5 (5): 69-80 .URL :http://shenakht.muk.ac.ir/article-1-582-fa.pdf

Copyright ( 2018 the Author (s). Published by Kurdistan University of Medical Sciences. This is an open access article distributed under the terms of the Creative Commons Attribution-Non Commercial License 4.0 (CCBY-NC), where it is permissible to download, share, remix, transform, and buildup the work provided it is properly cited. The work cannot be used commercially without permission from the journal. 


\title{
مرورى مختصر بر حساسيت اضطر ابى و اختلال وسواسى - جبرى
}

\author{
ساحل خاكِور'، فايق يوسفى '، اميد ساعد

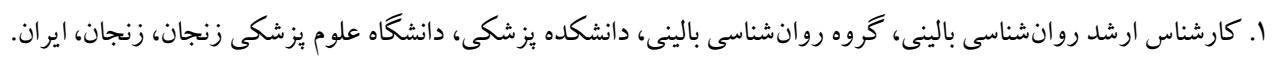

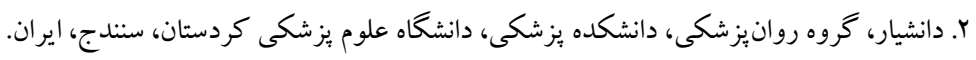

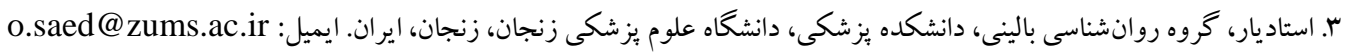

اختلال وسواسى - جبرى يكى از اختلالهاى روانى شايع است كه بر اكثر جنبههاى زندگى فرد اثر مى گذارد. در اين راستا مطالعات

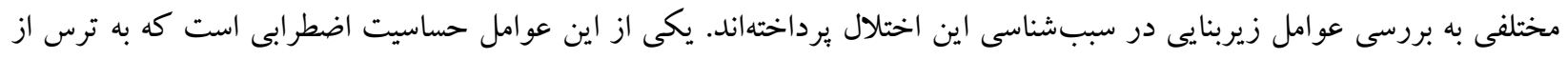

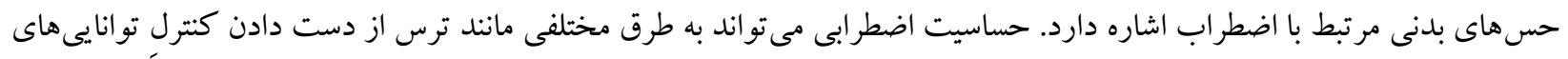

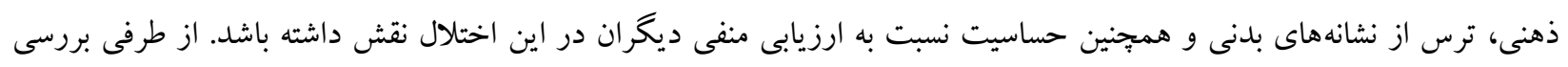

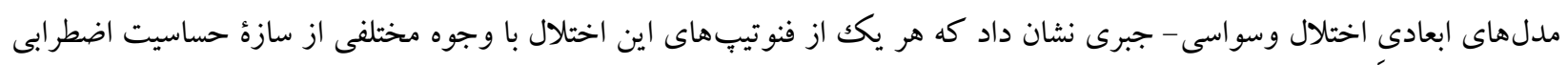

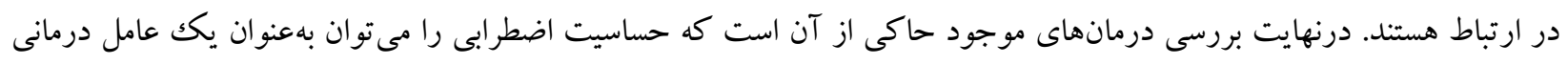

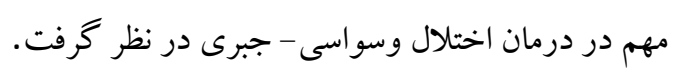
كلمات كليدى: حساسيت اضطر ابى، اختلال وسواسى - جبرى، مرور مختصر 
نشانهاى اجتماعى قابلمشاهده است (آسموندسون و

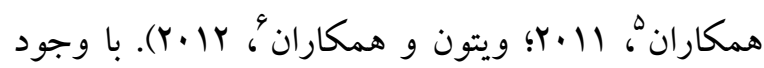
آنكه اين عامل در ابتدا در ارتباط با اختلال وحشت-

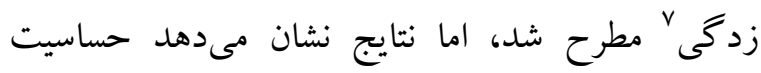
اضطرابى را مىتوان بهعنوان يك آسيب يذيرى زيربنايى براى ابتلا به اختلالهاى محور I در نظر كرفت (اشميت و

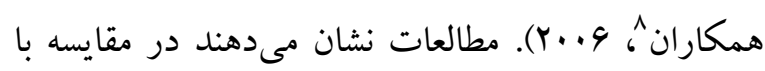
افراد سالم، بيماران وسواسى ميزان بيشترى از حساسيت

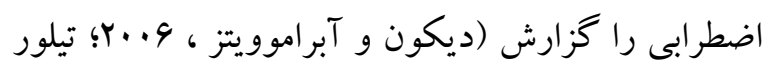

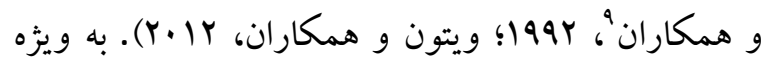
هرجه سطح حساسيت اضطرابى بالاتر باشد، شدت نشانهاى وسواسى در گروههاى بالينى و غير بالينى نيز

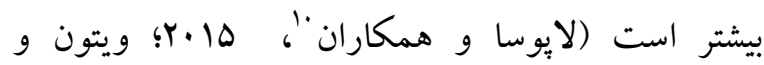

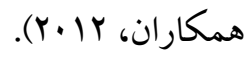

با توجه به مفهومسازى جندوجهى اين سازه و همجنين ويثز گىهاى روانشناختى اختلال وسواسى - جبرى مثل

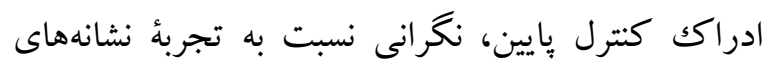
بدنى، گوشبهزنكى بالا و كمال گرايى به نظر مىرسد كه بتوان حساسيت اضطرابى را بهعنوان يك آسيبيذيرى مهمى در سببشناسى، تداوم و درمان اين اختلال در نظر كرفت؛ بنابراين مطالعه حاضر در تلاش است كه تا حد امكان ارتباط ميان حساسيت اضطرابى و اختلال وسواسى - جبرى را از منظر شروع، تداوم و درمان اين اختلال بررسى نمايد.

\section{حساسيت اضطرابى و نشانهاى اختلال وسواسى - جبرى}

\footnotetext{
${ }^{5}$.Asmundson, Weeks, Carleton, Thibodeau, \& Fetzner

${ }^{6}$ Wheaton, Deacon, McGrath, Berman, \& Abramowitz

${ }^{7}$.panic disorder

${ }^{8}$.Schmidt, Zvolensky, \& Maner

${ }^{9}$. Koch

${ }^{10}$.Laposa, Collimore, Hawley, \& Rector
}

مقدمه

اختلال وسواسى - جبرى' اختلالى است كه با نشانهاى وسواس فكرى شامل افكار، تصاوير و يا تكانهاى عودكننده و بيايدارى كه به شكلى مزاحم و ناخواسته تجربه مىشوند و همجينين با رفتارها يا اعمال ذهنى تكرارى و وقت گير، مشخص مىشود. اين افكار و اعمال موجب رنج بسيار و مختل شدن جشم گير عملكرد فرد در ور وري حوزههاى مختلف مىشوند (انجمن روانيزشكى آمريكا، rا •Y). بهمنظور دركك بهتر كاركرد وسواسها و اجبارها، مطالعات به بررسى تجربههاى هيجانى و درونى افراد مبتلابه اختلال وسواسى- جبرى يرداختند و عوامل مختلفى را شناسايى كردند. يكى از عواملى كه اخيراً مورد توجّه بثزوهشخران قرار گرفته است سازهُ حساسيت اضطر ابى 'است.

حساسيت اضطرابى يك سبك شناختى است كه ترس

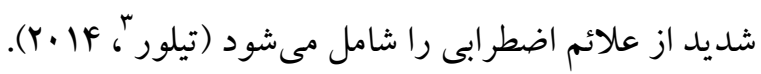
افرادى كه به علائم اضطرابى بسيار حساس هستند، باور دارند علائم اضطر ابى، ييامدهاى خطرناك يا فاجعه آميزى مانند بيمارىهاى جسمانى و روانى، از دست دادن كنترل و خجالتزدگى را به دنبال دارند. اين افراد از نظر تعداد دفعات تجربهُ علائم اضطرابى و ترس از اين علائم با يكديخر متفاوت هستند (رايس و همكاران؛؛ (1919). نتايج حاصل از تحليلهاى عاملى نشان مىدهد كه حساسيت اضطرابى سازهاى سلسله مراتبى و جندوجهى است كه شامل عاملهاى سطح بالا (حساسيت اضطرابى كلى) و عاملهاى سطح بِيين شامل ترس از حسهاى بلنى، ترس از دست دادن كنترل شناختى و ترس از

\footnotetext{
${ }^{1}$.obsessive compulsive disorder

2 . Anxiety Sensitivity

${ }^{3}$.Taylor

${ }^{4}$.Reiss, Peterson, Gursky, \& McNally
} 
حساسيت اضطر ابى و نشانههاى وسواسى حمايت كردهاند

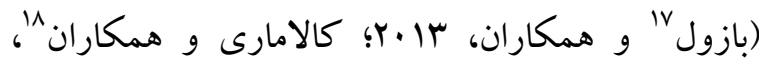

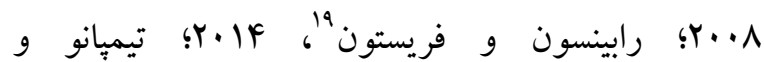

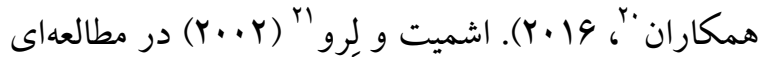
به بررسى ارتباط حساسيت اضطرابى و كنترل ادراككشده در ايجاد نشانهاى اضطر ابى برداختند. مطالعه آنان نشان داد كه حساسيت اضطرابى از طريق كنترل ادراكشده مى تواند نشانهاى اضطرابى را بيشبينى كند. مطالعهُ

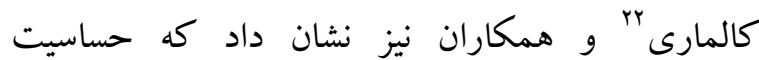
اضطرابى با باورهاى مربوط به كنترل و اهميت افكار در بيماران وسواسى ارتباط دارد (كالامارى و همكاران،

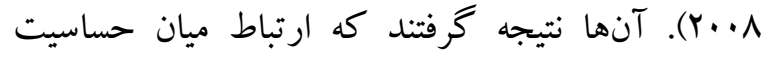
اضطرابى و باورهاى مربوط به بيش اهميتدهى به افكار

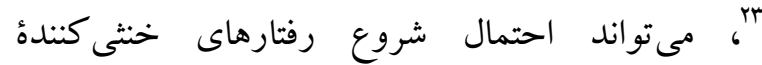

$$
\text { اضطراب مَr را افزايش دهد. }
$$

از طرفى برخى از افراد مبتلا به اختلال وسواسى- جبرى

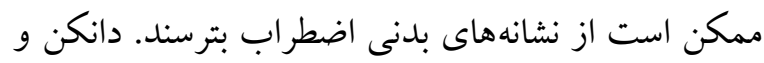

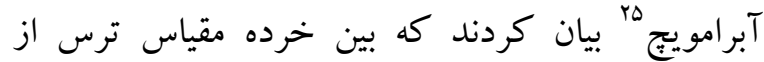
حسهاى بدنى و وسواس رابطه وجود دارد (ديكون و

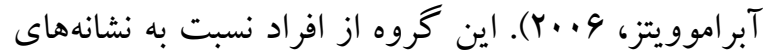
بدنى خود گوشبهزنگك هستند و بيش از اندازه به آنها توجه مى كنند. درواقع آنها نخراناند كه در اثر تجربهُ اضطراب شديد، كنترل ذهنى خود را از دست بدهند. علاوه بر اين، برخى از بيماران وسواسى در واكنش به

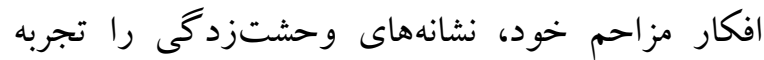

${ }^{17}$.Boswell

${ }^{18}$.Calamari, Rector, Woodard, Cohen, \& Chik

${ }^{19}$.Robinson \& Freeston

${ }^{20}$.Timpano, Raines, Shaw, Keough, \& Schmidt

21. Schmidt and Lerew

22. Calamari

${ }^{23}$. overimportance

${ }^{24}$. anxiety-neutralizing behaviors

${ }^{25}$. Deacon \& Abramowitz
يكى از ويثز گیىهاى مطرح شده در ارتباط با اختلالهاى

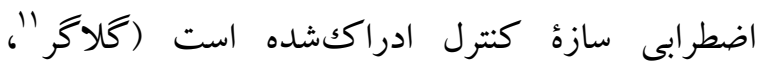

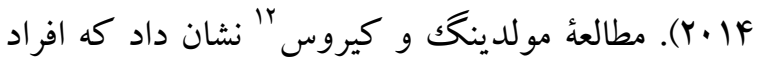
مبتلا به اختلال وسواسى-جبرى ميل به كنترل بالا و احساس كنترل بياينى دارند (مولدينگك و كيروس،

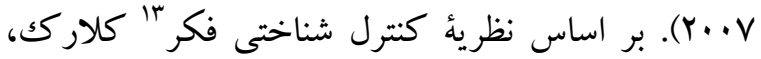
افراد مبتلابه اختلال وسواسى -جبرى احساس مى كنند كه كنترل كافى بر افكار مزاحم خود ندارند (امير و

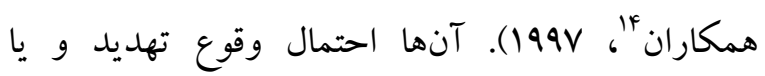
ييامدهاى منفى رويدادها را بيش از اندازه ارزيابى

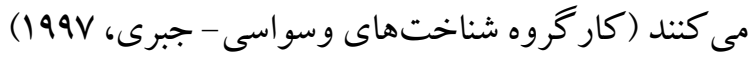
و به افكار خود بيش از حد اهميت مىدهند(فاواهام و

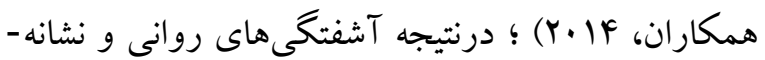
هاى فكرى و رفتارى وسواس را تجربه مى كنند. تفكر جادويى يكى ديخر از ويز گیىهاى افراد مبتلا به اختلال وسواسى-جبرى است و سبب مىشود كه بيماران باور داشته باشند افكارشان بيامدهاى نامطلوبى را به دنبال دارد. بنابر اين مىتوان كفت افكار مزاحم و ميل به كنترل آنها يكى از نكرانىهاى اصلى اين افراد است. از طرفى اين افراد فكر خود را با رفتار برابر مىدانند، ويز كى كه به آن آن آميختخى فكر -عمل "19 مى گويند. اين بيماران نخر انداند كه با از دست دادن كنترل افكار، كنترل رفتار خود را نيز از دست بدهند. درواقع به نظر مىرسد كه حساسيت اضطر ابى از طريق ترس از دست دادن كنترل شناختى با نشانهاى اختلال وسواسى - جبرى در ارتباط باشد. اكثر مطالعات از ارتباط بين خرده مقياس نكرانىهاى شناختى

${ }^{11}$.Gallagher, Bentley, \& Barlow

${ }^{12}$. Moulding \& Kyrios

13. Cognitive Thought Control

${ }^{14}$.Amir, Cashman, \& Foa

${ }^{15}$.Fava

16. Thought Action Fusion 
حساساند. علاوه بر اين برخى از بيماران وسواسى مى -

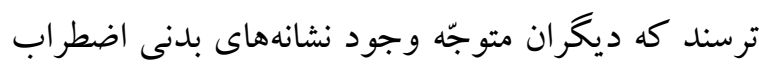
در آنها شوند و آنان را مورد ارزيابى منفى قرار دهند

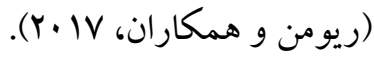

حساسيت اضطرابى و ابعاد اختلال وسواسىجبرى

علىرغم نتايج بالا، برخى مطالعات ارتباط متوسط تا

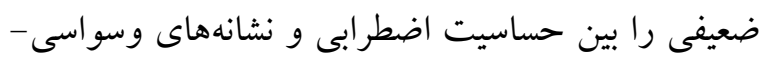
جبرى در مقايسه با ساير نشانهاى اضطرابى، مثل اضطراب اجتماعى يا وحشتزدگى، كزارش كردهاند

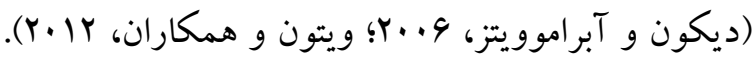
نكته قابلتوجه اين است كه اين مطالعات اختلال

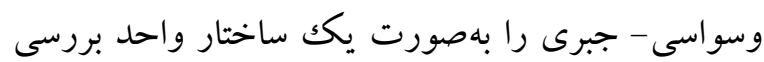
كردهاند، درحالى كه اين اختلال با فنوتيِهاى متنوعى

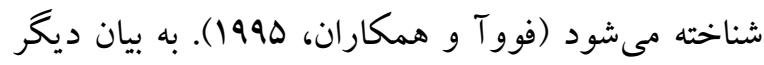
در نظر كرفتن اختلال وسواسى- جبرى بهعنوان يك إنك ساختار واحد مى تواند نقش حساسيت اضطر ابى در سببشناسى اين اختلال را كمرنغك كند. مدلهاى ابعادى عموماً نشانهاى اختلال وسواسى- جبرى را در ئ بُعبد

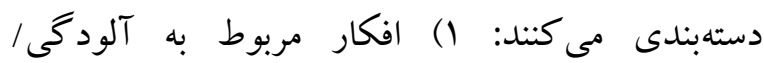
رفتارهاى شتشتو r) اشتغال ذهنى با مسئوليت/ رفتارهاى وارسى ؟) افكار مربوط به نظم و تقارن/ رفتارهاى نظم و

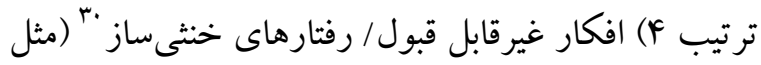

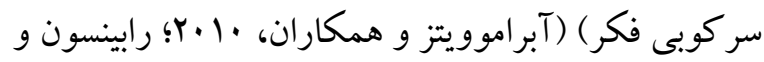

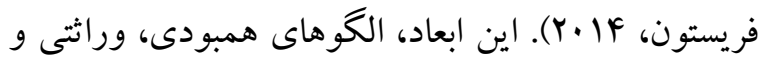

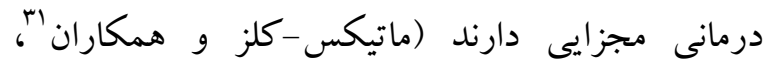

$(Y \cdots \Delta$

${ }^{30}$. Neutralizing compulsions

${ }^{31}$.Mataix-Cols, Rosario-Campos, \& Leckman

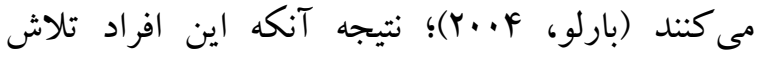

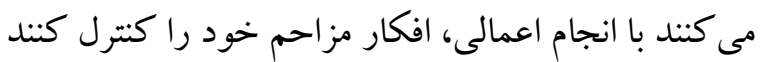
تا اضطراب ناشى از وجود اين نشانهاى بدنى و حالت

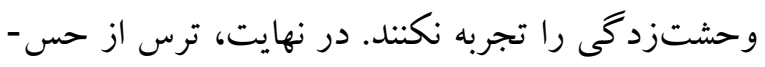
هاى بدنى مىتواند با وسواسهاى مرتبط با آلودگى در اين افراد مرتبط باشد. اين خروه از بيماران وسواسى نشانه هاى بدنى خود را بيش بر آورد مى كند و بيش آكهى بيمارىهاى جسمانى خود را ضعيف در نظر مى گيرند

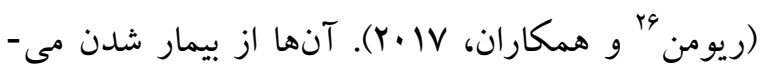
ترسند و نغراناند كه نشانهاى بدنى، نشانهاى از ابتلا به يكك بيمارى جسمى جدى باشد. يكى ديغر از ويزگ مهاى افراد مبتلابه اختلال وسواسى جبرى، داشتن استانداردهاى سطح بالا است كه با كمالكرايى، احساس كناه و مسئوليت بيش از حد ارتباط دارد. از نظر اين افراد افكار ناخواستهاى كه در شرايط استرسزا ايجاد مىشوند، غيرقابلقبولاند و علامتى از خطر يا شكست بالقوه هستند؛ بنابراين فرد در قِبال آنها مسئول

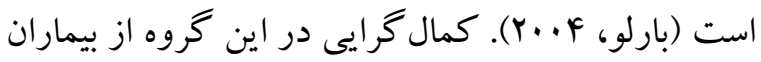
شامل نخرانى در مورد اشتباهات، انتظارات بيرونى و انتقاد

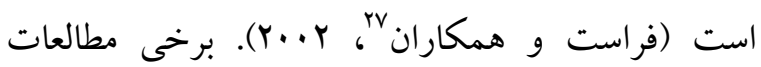
ارتباط معنادارى را بين خرده مقياس نغرانىهاى اجتماعى هرئ و نشانهاى وسواس تقارن و همجنين رفتارهاى وارسى نقى

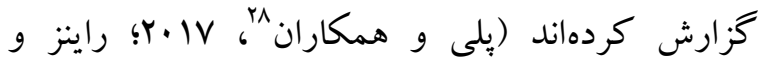

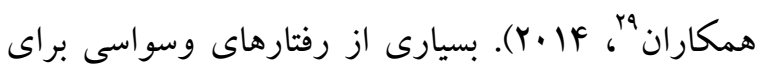
جلو گيرى از اشتباه و همجنين اجتناب از سرزنش ديخران

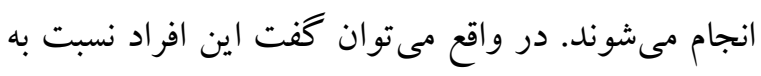
ارزيابى منفى ديخران و سرزنش شدن از سوى آنها

\footnotetext{
${ }^{26}$.Reuman

${ }^{27}$.Frost, Novara, \& Rhéaume

${ }^{28}$.Poli, Melli, Ghisi, Bottesi, \& Sica

${ }^{29}$.Raines, Oglesby, Capron, \& Schmidt
} 
حساسيت اضطرابى به بهترين وجه مىتواند استفاده از خدمات بهداشتى را ييشينى كند (ونكلف و همكاران،

.$(Y \cdot V$

نتايج مطالعات حاكى از آن است كه حساسيت اضطرابى با افكار تكرارى مرتبط با مسئوليتيذيرى ارتباط دارد. مطالعه ويتون و همكاران نشان داد كه خرده مقياس نخر انىهاى شناختى (ترس از دست دادن كنترل) مى تواند

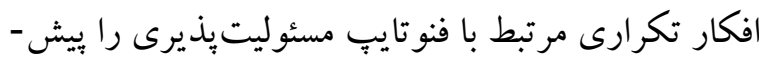
بينى كند (ويتون و همكاران، Y| (Y). بيمارانى كه اشتغال ذهنى اصلى آنها مسئوليتيذيرى است، اغلب شكك

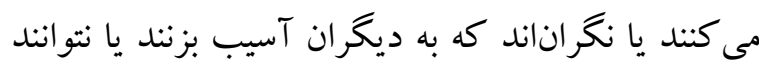
از آسيب بيشگيرى كنند. آنها تلاش مى كنند شك هاى خود را كنترل كنند يا از شر آنها خلاص شوند. اين كروه از افراد به توانايىهاى ذهنى خود براى توجّه به موقعيت و كنترل آن اطمينان ندارند و مىترسند در اثر بى توجهى، آسيبهايى را ايجاد كنند. از سوى ديخر اين افراد براى جلو گيرى از آسيب يا شكست احتمالى، دست به وارسى مىزنند. مطالعهُ رينز و همكاران نشان داد كه بين خرده مقياس نكرانى هاى اجتماعى و رفتارهاى وارسى

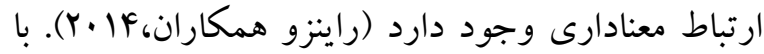
توجه به آنكه رفتارهاى وارسى اغلب قابل مشاهدهاند، به

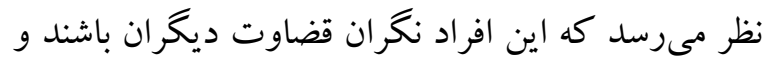

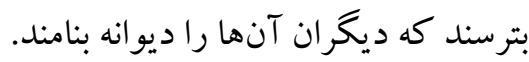
مطالعات انجامشده بر روى اختلال وسواسى- جبرى همجنين نشان دادند كه بين خرده مقياس هاى حساسيت اضطرابى و وسواس از نوع تقارن ارتباط وجود دارد

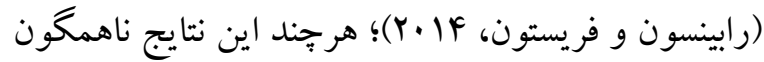
هستند. طبق مطالعهُ ويتون و همكاران خرده مقياس هاى ترس از دست دادن كنترل شناختى و نخر انىهاى بدنى
با وجود آنكه به نظر مىرسد بررسى اختلال وسواسىجبرى بهعنوان يكك ساختار جندبعدى به دركى دقيقتر ارتباط حساسيت اضطرابى با اين اختلال كمكك كند، مطالعات بسيار كمى به بررسى اين موضوع برداختهاند. نتايج اين مطالعات نشان مىدهد كه بين خرده مقياسهاى حساسيت اضطرابى و ابعاد مختلف نشانهاى وسواسى ارتباط معنادارى وجود دارد (كالامارى و همكاران،

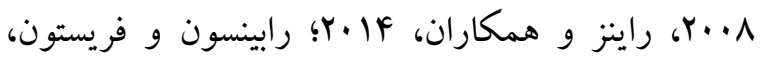

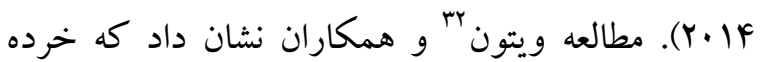
مقياس ترس از حسهاى بدنى مىتواند بهطور معنادارى

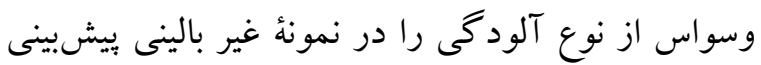

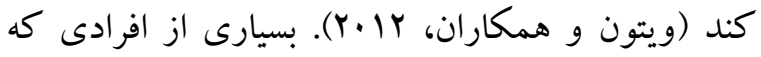
افكار وسواسى مرتبط با آلودگى دارند درواقع از بيمار شدن مىترسند. نكرانى هاى مرتبط با سلامتى در اين افراد احتمالاً با ترس از حس هاى بدنى همراه است. درواقع، آنها برخى از نشانهاى بدنى اضطراب را به غلط تفسير مى كنند و نكراناند كه مشكلات بدنى آنها علامتى از يكك بيمارى جدى باشند. از طرفى ديخر، مطالعهُ رينز "َّو همكاران نشان داد كه ارتباط معنادارى بين خرده مقياس ترس از حسهاى بلدى و رفتارهاى شستشو وجود ندارد

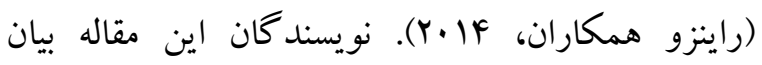
كردند كه رفتارهاى شستشو ممكن است بهجاى سازهء حساسيت اضطرابى با بخش ديخرى از نظرية انتظارى

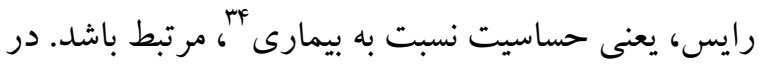
مطالعهاى كه در سال V...PV صورت گرفت مشخص شد كه حساسيت نسبت به بيمارى بهترين بيشبينى كننده رفتارهايى است كه سلامتى فرد را حفظ مى كنند (مثل

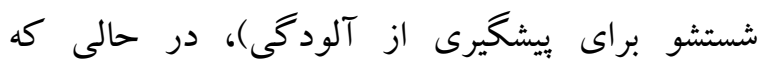

\footnotetext{
${ }^{32}$. Wheaton

${ }^{33}$. Raines

${ }^{34}$. illness sensitivity
} 
دادهاند. با تداوم اين روند افراد وسواسى كه افكار غيرقابل قبولى دارند، نكراناند كه از دست دادن كنترل توانايىهاى شناختى منجر به از دست دادن كنترل رفتارها در آينده شود. اين افراد افكار خود را غيرقابل قبول مى دانند و تلاش مى كنند آنها را از ديخران مخفى كنند، زيرا نخراناند كه از سمت ديخران مورد قضاوت قرار كيرند و سرزنش شوند (نيوت و راجمن، إ. (Y). اين افراد حتّى مىترسند كه نشانهاى اضطرابى آنها به عنوان علامتى مبنى بر وجود افكار غيرقابل قبولشان تلقى شود

$$
\text { (ويتون و همكاران، Y (Y. (Y). }
$$

\section{حساسيت اضطرابى و درمان اختلال وسواسى- جبرى} نشانهاى وسواسى- جبرى در Y تا r درصد مبتلايان، موجب بريشانى قابل توجه و نقص عملكرد مى شود (كسلر

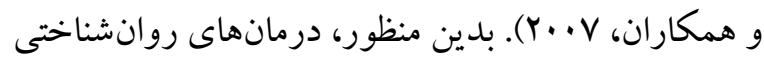
متعددى براى اختلال وسواسى - جبرى بيشنهاد شده است. با توجه به شواهد موجود مبنى بر ارتباط حساسيت اضطرابى و اختلال وسواسى- جبرى، به نظر مىرسد درمانهايى كه اين سازهُ شناختى را هدف قرار مىدهند، بتوانند بر كاهش نشانهاى وسواسى نيز اثر بحذارند. بازول ^ّو همكاران در مطالعه خود به بررسى اثر درمان فرا تشخيصى در كاهش حساسيت اضطرابى و نشانهاى اضطر ابى برداختند. علىرغم آنكه نتايج اين مطالعه ارتباط

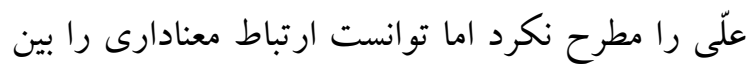

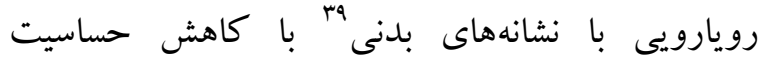

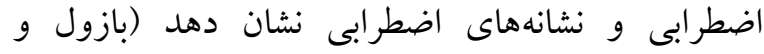
همكاران، سا.ب). رويارويى با نشانهاى بدنى به طور

${ }^{38}$.Boswell

${ }^{39}$. interoceptive exposure
مى تواند نشانههاى وسواس تقارن را در گروه غيربالينى

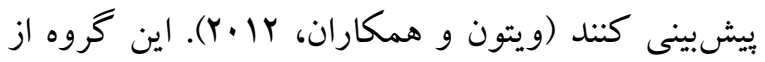
افراد وسواسى تمايل دارند كه كارها را دقيق و بدون كوجِكترين اشتباهى انجام دهند و كنترل امور را در

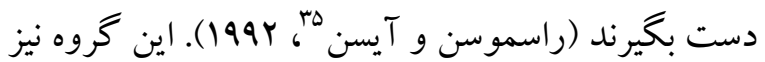
مانند دستهُ قبل به توانايىهاى ذهنى خود براى كنترل

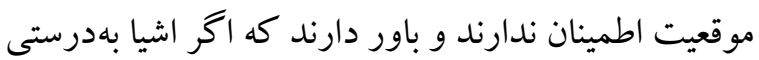
سر جاى خود قرار نخيرند، نمى توانند به خوبى با موقعيت كنار بيايند و اضطراب و آشفتكى نامحدودى را تجربه

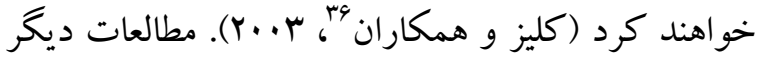
ارتباط معنادارى را بين خرده مقياس نخرانىهاى اجتماعى وهي و نشانهاى وسواس تقارن كزارش كردند (يلى و و

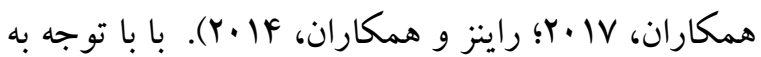
اينكه رفتارهاى وسواسى مرتبط با اين بُعد از نشانههاى وسواسى نيز اغلب قابلمشاهده است، طبيعى به نظر مىرسد كه اين گرووه از بيماران نسبت به قضاوتهاى ديخران و بر جّب خوردن از سَمت آنها حساس باشند. درنهايت طبق مطالعات انجامشده بين خرده مقياس نغرانىهاى شناختى و اجتماعى حساسيت اضطرابى و افكار غيرقابل قبول تكرارى ارتباط وجود دارد (راينز و

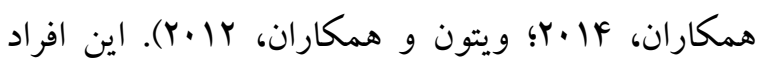
افكار خود را بيش از اندازه بااهميت ارزيابى مى كنند و احساس مى كنند كه كنترلى بر روى آنها ندارند. آنها تلاش بيشترى براى كنترل اين افكار مى كنند اما از آنجايى كه سركوب افكار عموماً با شكست همراه است

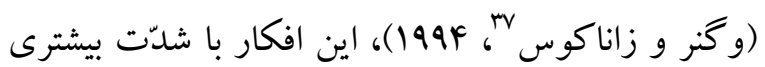
تداوم مىيابند. اين گروه از بيماران وسواسى گمان مى كنند كه كنترل توانايىهاى شناختى خود را از دست

\footnotetext{
${ }^{35}$.Rasmussen \& Eisen

${ }^{36}$.Coles, Frost, Heimberg, \& Rhéaume

${ }^{37}$.Wegner \& Zanakos
} 
اضطرابى عز در اين گروه از بيماران مى گردد. درواقع بيماران وسواسى با حساسيت اضطرابى بالا، علاوه بر محركى كه با آن مواجه شدهاند، از احساسات بدنى خود حين رويارويى نيز مىترسند، درست مانند حالتى كه در

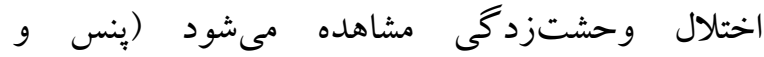
همكاران كه حساسيت اضطرابى بالايى نيز دارند، در حين رويارويى ممكن است حملات وحشتزدگى را تجربه كنند كه اين خود اجتناب را افزايش و همكارى در درمان

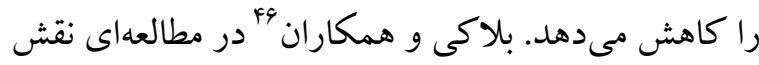
حساسيت اضطر ابى در بيامدهاى درمان شناختى رفتارى بيماران وسواسى را بررسى نمودند (بلاكى و همكاران

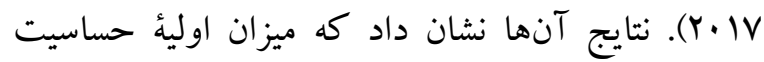
اضطرابى مىتواند شدّت نشانهاى وسواسى، در اين بيماران را يّ از درمان بيشبينى كند (هرجه ميزان

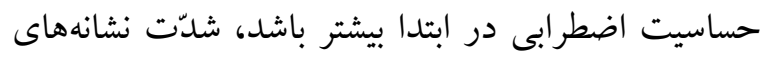
وسواسى، يس از درمان نيز بيشتر خواهد بود).

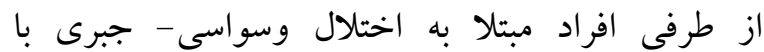
حساسيت اضطرابى بالا، عملكردى مختل دارند و و اضطراب بالايى تجربه مى كنند. اين حالت ممكن است موجب شود كه اعضاى خانواده و اطرافيان آنها، دست به رفتارهايى بزنند كه آشفتگى اين بيماران را در كوتاه

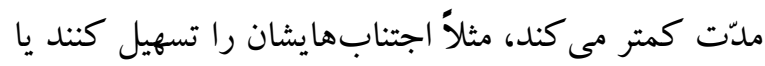
در آعمال اجبارىشان مشاركت نمايند (ويو مَّ همكاران، 19 (Y) . درواقع مى توان كفت عملكرد و ساختار خانو اده مى تواند در تداوم اين اختلال نقش داشته باشد. مطالعات

${ }^{44}$. anxious arousal

${ }^{45}$.Pence Jr, Sulkowski, Jordan, \& Storch

${ }^{46}$. Blakey et al.

${ }^{47}$.Blakey, Abramowitz, Reuman, Leonard, \& Riemann

${ }^{48} . \mathrm{Wu}$
سنتى راهبردى براى كاهش حساسيت اضطرابى و درنتيجه، كاهش نشانهها در اختلال بنيك در نظر كرفته مىشد، اما امروزه به نظر مىرسد كه اين راهبردى براى بيشتر اختلالهاى اضطرابى كاربرد داشته باشد. رينز و همكاران در كارآزمايى خود اثر مداخلهُ كوتاهدّت در كاهش نكرانى هاى شناختى حساسيت

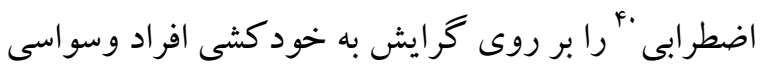

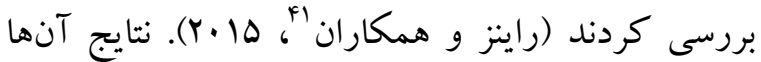
نشان داد كه اين درمان از طريق كاهش بُعد شناختى حساسيت اضطرابى مىتواند گرايش به خودكشى را در

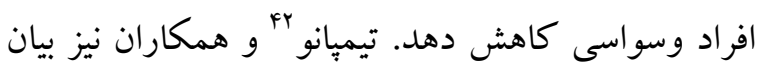
كردند كه مداخلهُ كوتاهمدت كاهش حساسيت اضطر ابى، مى تو اند با كاهش حساسيت اضطرابى، نشانهاى فكرى و عملى وسواس را كاهش دهد (تيميانو و همكاران، 19) (Y. اين محققان بيشنهاد كردند كه با توجه به ماهيت جندبُعدى اختلال وسواسى- جبرى، مطالعات بعدى به بررسى اثر كاهش حساسيت اضطرابى در درمان ابعاد مختلف اين اختلال و تفاوتهاى آنها بيردازند. از سوى ديخر شواهدى وجود دارند كه لزوم بررسى حساسيت اضطرابى بهعنوان عامل بيشبينى كننده

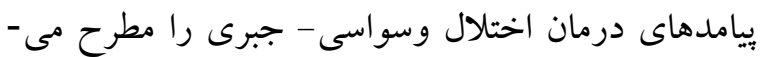
كند. براى مثال، علىرغم حمايتهاى تجربى كه از درمانهاى شناختى - رفتارى در درمان اختلال وسواسى جبرى صورت كرفته است، برخى از بيماران به اين درمانها به طور مناسب يُاسخ نمىدهند. علاوه بر اين، در

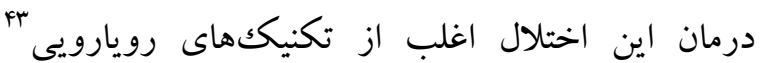
استفاده مىشود كه اين خودْ موجب برانگيختخى

\footnotetext{
${ }^{40}$. brief anxiety sensitivity cognitive concerns intervention

${ }^{41}$.Raines, Short, Allan, Oglesby, \& Schmidt

42. Timpano

43 . exposure
} 
به دركك هرجه بيشتر نشانهاى اختلال وسو اسى-جبرى و همجنين بهبود مدلهاى تبينى و فرايندهاى درمانى كمك كند. از اين منظر در مطالعه حاضر تلاش شد تا با ارائه شواهد نظرى و عملى، نقش ابعاد مختلف اين سازءٔ شناختى در ابتلا به اختلال وسواسى- جبرى و تداوم نشانهاى آن موردبررسى قرار گيرد. در نهايت با توجه به مطالعات مطرحشده مىتوان كفت، سازه حساسيت اضطرابى نقش قابلتوجهى در سببشناسى و درمان اختلال وسو اسى - جبرى دارد و بالينگر ان بايد به اين سازء شناختى و اثرات جندوجهى آن در كار با بيماران

$$
\text { وسواسى توجه كنند. }
$$

\section{References}

Abramowitz, J. S., Deacon, B. J., Olatunji, B. O., Wheaton, M. G., Berman, N. C., Losardo, D., . . . Hale, L. R. (2010). Assessment of obsessive-compulsive symptom dimensions: development and evaluation of the Dimensional Obsessive-Compulsive Scale. Psychol Assess, 22(1), 180-198. doi:10.1037/a0018260

Amir, N., Cashman, L., \& Foa, E. B. (1997). Strategies of thought control in obsessive-compulsive disorder. Behaviour research and therapy, 35(8), 775-IN771.

Asmundson, G. J., Weeks, J. W., Carleton, R. N., Thibodeau, M. A., \& Fetzner, M. G. (2011). Revisiting the latent structure of the anxiety sensitivity construct: more evidence of dimensionality. J Anxiety Disord, 25(1), 138147. doi:10.1016/j.janxdis.2010.08.013

Association, A. P. (2013). Diagnostic and statistical manual of mental disorders (DSM-5®): American Psychiatric Pub.

Barlow, D. H. (2004). Anxiety and its disorders: The nature and treatment of anxiety and panic: Guilford press.

Blakey, S. M., Abramowitz, J. S., Reuman, L., Leonard, R. C., \& Riemann, B. C. (2017). Anxiety
نشان دادند كه مساعدتهاى خانوادكى " بو بيامدهاى درمان اختلال وسواسى - جبرى اثر مى گذارد (ليبوويتج و

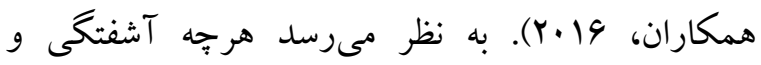
حساسيت اين بيماران بيشتر باشد، مساعدتهاى خانوادگى كه دريافت مى كنند نيز بيشتر مىشود. خنين شرايطى با اهداف درمانى رويارويى در تضاد است؛ يعنى بيمار كمتر با نشانهاى خود روبهرو مىشود. بر اساس مطالعه وُيو •ه و همكاران، حساسيت اضطرابى به طور معنادارى با مساعدت هاى خانو ادگى ارتباط دارد، به ويزه بُعد نگرانىهاى شناختى حساسيت اضطرابى مى تواند افزايش مساعدتهاى خانوادگى كسبشده توسط اين بيماران را بيشبينى كند (ويو و همكاران، 19 +r). اين مساعدتها با تقويت منفى نشانههاى وسواسى موجب تداوم آنها مىشوند و از ايجاد ارزيابىها و رفتارهاى ساز كارانهتر جلو گيرى مى كنند. از سوى ديخر نتايج بررسىها نشان مىدهند هرجه حساسيت اضطرابى در اعضاى خانواده و مراقبان بيمار بيشتر باشد، آنها بهاحتمال بيشترى درگير نشانهاى وسواسى عضو بيمار خانواده مىشوند و نشانهاى او را تقويت مى كنند (كاسنتينو، ها •Y). به بيانديخر ناتوانى

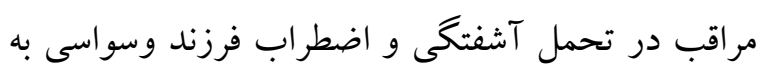
تشديد نشانهاى او منجر مى شود.

$$
\begin{aligned}
& \text { نتيجه كيرى }
\end{aligned}
$$

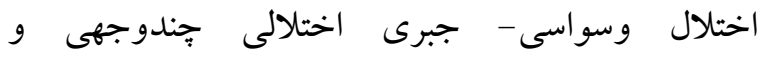

$$
\begin{aligned}
& \text { ناتوانكنده است و عوامل شناختى مختلفى در سبب- } \\
& \text { شناسى و تداوم آن دخيل هستند. حساسيت اضطرابى } \\
& \text { يكى از عوامل مطرح شده در اين حوزه است كه مىتواند }
\end{aligned}
$$

\footnotetext{
${ }_{50}^{49}$. Family accommodation
} 
disorder. Am J Psychiatry, 152(1), 90-96. doi:10.1176/ajp.152.1.90

Frost, R. O., Novara, C., \& Rhéaume, J. (2002). Perfectionism in obsessive compulsive disorder Cognitive approaches to obsessions and compulsions (pp. 91-105): Elsevier.

Gallagher, M. W., Bentley, K. H., \& Barlow, D. H. (2014). Perceived Control and Vulnerability to Anxiety Disorders: A Meta-analytic Review. Cognitive therapy and research, 38(6), 571584. doi:10.1007/s10608-014-9624-x

Group, O. C. C. W. (1997). Cognitive assessment of obsessive-compulsive disorder. Behaviour research and therapy, 35(7), 667-681.

Kessler, R. C., Angermeyer, M., Anthony, J. C., R, D. E. G., Demyttenaere, K., Gasquet, I, . . . Ustun, T. B. (2007). Lifetime prevalence and age-ofonset distributions of mental disorders in the World Health Organization's World Mental Health Survey Initiative. World psychiatry, 6(3), 168-176.

Laposa, J. M., Collimore, K. C., Hawley, L. L., \& Rector, N. A. (2015). Distress tolerance in OCD and anxiety disorders, and its relationship with anxiety sensitivity and intolerance of uncertainty. $J$ Anxiety Disord, 33, 8-14. doi:10.1016/j.janxdis.2015.04.003

Lebowitz, E. R., Panza, K. E., \& Bloch, M. H. (2016). Family accommodation in obsessivecompulsive and anxiety disorders: a five-year update. Expent Rev Neurother, 16(1), 45-53. doi:10.1586/14737175.2016.1126181

Mataix-Cols, D., Rosario-Campos, M. C., \& Leckman, J. F. (2005). A multidimensional model of obsessive-compulsive disorder. Am $J$ Psychiatry,162(2),228-238. doi:10.1176/appi.ajp.162.2.228

Moulding, R., \& Kyrios, M. (2007). Desire for control, sense of control and obsessive-compulsive symptoms. Cognitive therapy and research, 31(6), 759-772. doi:10.1007/ s10608 -006 9086-x

Newth, S., \& Rachman, S. (2001). The concealment of obsessions. Behav Res Ther, 39(4), 457-464.

Pence Jr, S. L., Sulkowski, M. L., Jordan, C., \& Storch, E. A. (2010). When exposures go wrong: sensitivity as a predictor of outcome in the treatment of obsessive-compulsive disorder. Journal of Behavior Therapy and Experimental Psychiatry, 57, 113-117. doi:10.1016/j.jbtep.2017.05.003

Boswell, J. F., Farchione, T. J., Sauer-Zavala, S., Murray, H. W., Fortune, M. R., \& Barlow, D. H. (2013). Anxiety sensitivity and interoceptive exposure: a transdiagnostic construct and change strategy. Behav Ther, 44(3), 417-431. doi:10.1016/j.beth.2013.03.006

Calamari, J. E., Rector, N. A., Woodard, J. L., Cohen, R. J., \& Chik, H. M. (2008). Anxiety sensitivity and obsessive - compulsive disorder. Assessment, 15(3),351-363.

Coles, M. E., Frost, R. O., Heimberg, R. G., \& Rhéaume, J. (2003). "Not just right experiences": perfectionism, obsessivecompulsive features and general psychopathology. Behaviour research and therapy, 41(6), 681-700.

Cosentino, T., Faraci, P., Coda, D., D'Angelo, R., De Pari, L. A., Di Crescenzo, M. R., ... Scelza, A. (2015). FAMILY ACCOMMODATION IN OBSESSIVE-COMPULSIVE DISORDER: A STUDY ON ASSOCIATED VARIABLES. Clinical Neuropsychiatry, 12(5).

Deacon, B., \& Abramowitz, J. (2006). Anxiety sensitivity and its dimensions across the anxiety disorders. J Anxiety Disord, 20(7), 837-857.doi:10.1016/j.janxdis.2006.01.003

Deacon, B., \& Abramowitz, J. (2006). Anxiety sensitivity and its dimensions across the anxiety disorders. Journal of anxiety disordens, 20(7), 837-857.

Fava, L., Bellantuono, S., Bizzi, A., Cesario, M., Costa, B., De Simoni, E., ... Iacono, A. L. (2014). Review of Obsessive Compulsive Disorders Theories. Global Journal of Epidemiology and Public Health, 1, 1-13.

Foa, E. B., Kozak, M. J, Goodman, W. K., Hollander, E., Jenike, M. A., \& Rasmussen, S. A. (1995). DSM-IV field trial: obsessive-compulsive 
Schmidt, N. B., \& Lerew, D. R. (2002). Prospective evaluation of perceived control, predictability, and anxiety sensitivity in the pathogenesis of panic. Journal of Psychopathology and Behavioral Assessment, 24(4), 207-214. doi:Doi 10.1023/A:1020795114296

Schmidt, N. B., Zvolensky, M. J., \& Maner, J. K. (2006). Anxiety sensitivity: prospective prediction of panic attacks and Axis I pathology. J Psychiatr Res, 40(8), 691-699. doi:10.1016/j.jpsychires.2006.07.009

Taylor, S. (2014). Anxiety sensitivity: Theory, research, and treatment of the fear of anxiety: Routledge.

Taylor, S., Koch, W. J., \& McNally, R. J. (1992). How does anxiety sensitivity vary across the anxiety disorders? Journal of anxiety disorders, 6(3), 249-259. doi:10.1016/0887-6185(92)90037-8

Timpano, K. R., Raines, A. M., Shaw, A. M., Keough, M. E., \& Schmidt, N. B. (2016). Effects of a brief anxiety sensitivity reduction intervention on obsessive compulsive spectrum symptoms in a young adult sample. J Psychiatr Res, 83, 8-15. doi:10.1016/j.jpsychires.2016.07.022

Vancleef, L. M. G., Peters, M. L., Gilissen, S. M. P., \& De Jong, P. J. (2007). Understanding the role of injury/illness sensitivity and anxiety sensitivity in (Automatic) pain processing: An examination using the extrinsic affective Simon task. Journal of Pain, 8(7), 563-572. doi:10.1016/j.jpain.2007.02.431

Wegner, D. M., \& Zanakos, S. (1994). Chronic thought suppression. JPers, 62(4), 616-640.

Wheaton, M. G., Deacon, B. J., McGrath, P. B., Berman, N. C., \& Abramowitz, J. S. (2012). Dimensions of anxiety sensitivity in the anxiety disorders: evaluation of the ASI-3. $J$ Anxiety Disord, 26(3), 401-408. doi:10.1016/j.janxdis.2012.01.002

Wheaton, M. G., Mahaffey, B., Timpano, K. R. Berman, N. C., \& Abramowit, J. S. (2012). The relationship between anxiety sensitivity and obsessive-compulsive symptom dimensions. J Behav Ther Exp Psychiatry, 43(3), 891-896.
Trouble-shooting guidelines for managing difficult scenarios that arise in exposure-based treatment for obsessive-compulsive disorder. American Joumal of Psychotherapy, 64(1), 39-53.

Poli, A., Melli, G., Ghisi, M., Bottesi, G., \& Sica, C. (2017). Anxiety sensitivity and obsessivecompulsive symptom dimensions: Further evidence of specific relationships in a clinical sample. Personality and Individual Differences, 109, 130-136. doi:10.1016/j.paid.2017.01.002

Raines, A. M., Oglesby, M. E., Capron, D. W., \& Schmidt, N. B. (2014). Obsessive compulsive disorder and anxiety sensitivity: Identification of specific relations among symptom dimensions. Journal of Obsessive-Compulsive and Related Disorders, 3(2), 71-76. doi:10.1016/j.jocrd.2014.01.001

Raines, A. M., Short, N. A., Allan, N. P., Oglesby, M. E., \& Schmidt, N. B. (2015). Examination of a brief anxiety sensitivity cognitive concerns intervention on suicidality among individuals with obsessive-compulsive symptoms. Contemp Clin Trials, 45(Pt B), 191-195. doi:10.1016/j.cct.2015.09.006

Rasmussen, S. A., \& Eisen, J. L. (1992). The epidemiology and clinical features of obsessive compulsive disorder. Psychiatr Clin North Am, 15(4), 743-758.

Reiss, S., Peterson, R. A., Gursky, D. M., \& McNally, R. J. (1986). Anxiety sensitivity, anxiety frequency and the prediction of fearfulness. Behav Res Ther, 24(1), 1-8.

Reuman, L., Jacoby, R. J., Blakey, S. M., Riemann, B. C., Leonard, R. C., \& Abramowit, J. S. (2017). Predictors of illness anxiety symptoms in patients with obsessive compulsive disorder. Psychiatry Res, 256, 417-422. doi:10.1016 jj.psychres.2017.07.012

Robinson, L. J., \& Freeston, M. H. (2014). Emotion and intemal experience in Obsessive Compulsive Disorder: reviewing the role of alexithymia, anxiety sensitivity and distress tolerance. Clin Psychol Rev,34(3), 256-271. doi:10.1016/j.cpr.2014.03.003 
Wu, M. S., McGuire, J. F., \& Storch, E. A. (2016). Anxiety sensitivity and family accommodation in obsessive-compulsive disorder. I Affect Disord, 205, 344-350. doi:10.1016/j.jad.2016.08.024
Wu, M. S., McGuire, J. F., Martino, C., Phares, V., Selles, R. R., \& Storch, E. A. (2016). A metaanalysis of family accommodation and $\mathrm{OCD}$ symptom severity. Clin Psychol Rev, 45, 34 44. doi:10.1016/j.cpr.2016.03.003 